\title{
PRESUPPOSITIONS IN MECHANICAL ENGINEERING DISCOURSE
}

\author{
JEKATERINA ČERN̦EVSKA
}

University of Latvia, Latvia

\begin{abstract}
With the development of pragmatics as a subfield of applied linguistics, the semantics-pragmatics interface has received a considerable amount of attention among both semanticists and pragmaticians. However, little research has been conducted on the pragmatic meaning construction in mechanical engineering discourse. Presupposition is a concept in the philosophical and linguistic tradition, which can be defined as a background assumption required in order to construct the utterance meaning in the context of use. The aim of the present study is to discuss the linguistic features and the contextual information necessary for a presupposition to occur in an utterance. The present research draws its data from the analysis of the chapters on woodworking and metal processing from the Encyclopaedia of Occupational Health and Safety. The research has been approached from the qualitative perspective. The research method is discourse analysis. The research has resulted in a conclusion that the most frequently utilized presupposition triggers in the discourse under analysis are temporal clauses and change of state verbs. The presuppositions are both linguistically triggered and depend on the contextual information. However, presuppositions usually complement rather than override one another, which can serve as an indicator of the complementary nature of the relationship between the semantic and the pragmatic parts of the linguistic meaning. The interaction between other aspects of semantic and pragmatic meaning can be considered a matter of further investigation.
\end{abstract}

Key words: mechanical engineering discourse, pragmatic meaning, presupposition, semantics-pragmatics interface

\section{INTRODUCTION}

The boundary between semantics and pragmatics has been a matter of numerous debates among scholars. Huang (2007: 241) offers a comprehensive analysis of such prominent theoreticians' as Grice, Sperber and Wilson, Levinson, Bach and Recanati stance on the distinction between the semantic and the pragmatic aspects of meaning. The interaction between semantics and pragmatics is typically referred to as the semantics-pragmatics interface. Generally speaking, the aspects of meaning form a continuum from the semantic representation 
(or the linguistic form) of an utterance to the additional propositions (or implicatures) that can be triggered by an utterance in its context of use.

Presupposition can be regarded as one of the central phenomena related to the distinction between the linguistic form and the non-linguistic (or contextual) aspects of meaning. It is a technical term that defines a proposition, the truth of which is taken for granted (Huang, 2012: 245). 'The main function of a presupposition is to act as a precondition or presumption of some kind for the appropriate use of the sentence' (ibid.).

The goal of the present study is to investigate how the linguistic meaning contributes to constructing presuppositions in the context of mechanical engineering discourse. The research is focused on presupposition triggers, which Levinson (1983: 181-185) classifies into 13 lexical and syntactic groups. Factive verbs (e.g. to regret, to realize), implicative verbs (e.g. to manage, to avoid), change of state verbs (e.g. to stop, to continue) and temporal clauses are some of the examples of presupposition triggers. The research analyses how the semantic aspects of meaning represented by the presupposition triggers interfere with the context of professional discourse.

It has been hypothesised that a presupposition can survive in the context only when it is consistent with the background assumptions that can be accessed by the target audience of the discourse. The hypothesis is rooted in Gazdar's presupposition cancellation analysis (1979, discussed in Huang, 2007: 83).

The research questions have been set: what is the frequency of the presupposition trigger occurrence in the discourse under analysis? What is the impact of the context on the semantic presupposition triggers?

The paper offers a theoretical discussion on the concept of presupposition and its role in the semantics-pragmatics interface. The empirical part is focused on the presupposition trigger frequency and the analysis of the selected utterances containing presupposition triggers.

\section{LITERATURE REVIEW}

In order to be embedded in the semantic theories of meaning, presupposition was assigned the status of a special type of entailment (Levinson, 1983: 199). Entailment is a logical concept that determines the relationships between the propositions in terms of truth and falsehood. 'A sentence $p$ entails a sentence $\mathrm{q}$ when the truth of the first guarantees the truth of the second, and the falsity of the first guarantees the falsity of the second' (Saeed, 2003: 98). The basic properties of entailment are its non-cancellability and non-detachability from the content of 'what is said' (or the linguistic form of an utterance).

On balance, 'A semantically presupposes B iff [if and only if - J.Č.]: (a) in all situations where A is true, B is true; (b) in all situations where A is false, B is true' (Levinson, 1983: 175). In other words, presupposition deals with the fact that $B$ remains true even if we do not know whether $\mathrm{A}$ is true or false. For instance, an 
utterance like 'Employees should be made aware of the safe operating practices necessary for the proper use of various woodworking saws' (Stellman and Parish (eds.), 2011, Chapter 86: Online) contains a factive predicate 'to be aware of' which presupposes that safe operating practices necessary for the proper use of various woodworking saws exist even in case when the employees should not be aware of these practices. This phenomenon is defined as 'survival under negation' or 'constancy under negation', which is a property of presupposition (Levinson, 1983; Huang, 2007) and, thus, distinguishes it from entailment.

Cancellability is another basic property of presupposition (Huang, 2007: 67). Whereas entailments cannot be cancelled without causing a semantic anomaly, presuppositions can be cancelled in the context of their use. Gazdar (1979, discussed in Huang, 2007: 83) proposed cancellation analysis of presuppositions. He argued that the procedure includes several stages in order of priority: background assumptions, contextual factors, semantic entailments, conversational implicatures, and presuppositions. In other words, presuppositions survive only if they are consistent with other aspects of meaning.

Mey (1993: 184) states that semantic presuppositions deal with truth and falsity of a sentence, which does not provide an adequate framework for the analysis of the pragmatic meaning.

According to Ariel (2010: 156), there are two distinct aspects of presupposition - semantic (the linguistically encoded part) and pragmatic (the inferred part). Therefore, if a writer commits him/herself to the truth of the proposition, he or she can either use presupposition triggers or allow the reader to infer this commitment from the context (or both).

Another distinction can be drawn between presuppositions and conversational implicatures. Although both are pragmatic concepts, 'valid presuppositions tend to remain mostly implicit, while valid implicatures rise to the surface and become visible in the course of conversation' (Mey, 1993: 188). Mey adds that once pragmatic presuppositions are accepted, they are added to the context, while conversational implicatures tend to shift in the course of communication. Besides, 'implicatures are mainly the individual's own business; presuppositions require a collective, sometimes even metapragmatic justification' (ibid.: 189).

Pragmatic presupposition can be compared to the notion of implicated premises in the relevance-theoretical framework. Sperber and Wilson (1995: 195) suggest that the addressee either retrieves implicated premises from his/her background assumptions or constructs them by developing new assumptions. This stance mostly corresponds to the definition of presupposition that is identified as a proposition the truth of which is taken for granted in the context of use. The pragmatically presupposed information necessary for understanding an utterance is taken into consideration in the course of the inferential process during the communicative act. The difference between presupposition and implicated premises might be in the assumption that presupposition behaves 
more stable in the context, whereas implicated premises is a type of implicature and, thus, can be a matter of the individual's interpretation of the context.

Levinson (1983: 181-185) provides an extensive list of presupposition triggers. This list includes: definite descriptions (e.g. the man with two heads), factive verbs (e.g. to regret, to realize) and predicates (e.g. to be aware, to be glad that, to be sad that), implicative verbs (e.g. to manage, to forget, to intend), change of state verbs (e.g. to stop, to begin, to continue), iteratives (e.g. again, to come back, to repeat), verbs of judging (e.g. to accuse, to criticize), temporal clauses (e.g. before, while, still), cleft sentences, comparisons and contrasts (e.g. too, back, better), nonrestrictive relative clauses, counterfactual conditionals and questions. The triggers can be classified into lexical and syntactic presupposition.

\section{METHODS}

The present study has been approached from the qualitative perspective with the elements of the quantitative research. The present research is cross-sectional and comprises a snapshot-like analysis of the target phenomenon at one particular point in time' (Dörnyei, 2007: 78). The study embodies an explanatory case study research type. The primary research method is discourse analysis.

The corpus for the analysis comprises two chapters borrowed from the Encyclopaedia of Occupational Health and Safety (Stellman and Parish (eds.), 2011). The chapters focus on such subareas of mechanical engineering as wood processing and metal processing. The selected corpus comprises 58,293 tokens of 51,201 words.

The first step is the analysis of the frequency of the presupposition triggers that aims to obtain the data about the semantic aspect of presuppositions. The analysis was conducted utilizing the SketchEngine software. Then the selected utterances were analysed in order to demonstrate how the semantic aspect of meaning correlates with the pragmatic aspect (i.e. background assumptions).

\section{RESULTS AND DISCUSSION}

The findings comprise the obtained data regarding the frequency of lexical and syntactic presupposition triggers in the corpus. The aim of this step was to investigate the examples of use of semantic presupposition triggers in the context of the professional discourse of mechanical engineering. Figure 1 illustrates the proportional distribution of the semantic presupposition trigger groups identified in the corpus.

The results demonstrate that the most commonly represented presupposition triggers in the discourse under analysis are change of state verbs and temporal clauses. The results can be explained by the focus on the sequence of steps in the material processing procedure, which should usually last for an exact temporal period and lead to the material's change of state. 


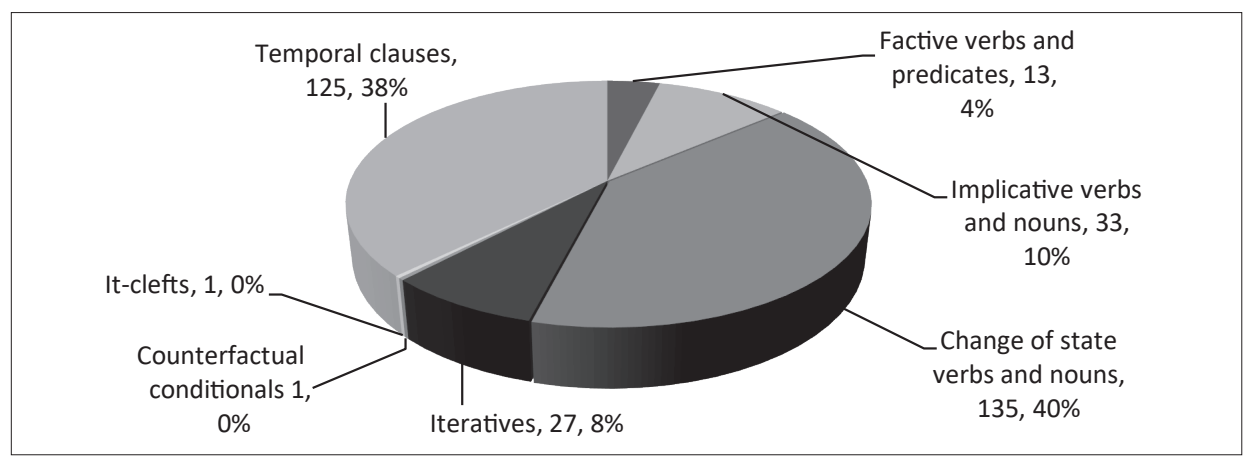

Figure 1 Proportional distribution of semantic presupposition triggers in the discourse

The semantic presupposition trigger groups can consist of a number of linguistic items. For instance, the group of factive verbs and predicates has been represented in the discourse via three linguistic units - 'to know', 'to be aware of' and 'to remember'. Table 1 demonstrates the frequency of the semantic presupposition trigger occurrence in the discourse. The triggers are utilized as different parts of speech.

Table 1 The linguistic realization of the semantic presupposition triggers and the frequency of the linguistic unit occurrence

\begin{tabular}{|l|l|}
\hline \multicolumn{1}{|c|}{$\begin{array}{c}\text { Presupposition trigger } \\
\text { group }\end{array}$} & \multicolumn{1}{|c|}{$\begin{array}{c}\text { The presupposition trigger linguistic realization and } \\
\text { frequency of occurrence }\end{array}$} \\
\hline Factive verbs and predicates & To know -8 , to be aware of -4 , to remember -1 \\
\hline Implicative verbs and nouns & To happen -4 , to avoid -28 , attempt -1 \\
\hline $\begin{array}{l}\text { Change of state verbs and } \\
\text { nouns }\end{array}$ & $\begin{array}{l}\text { Stop }-7 \text {, to begin }-3 \text {, to continue }-8 \text {, start }-23 \text {, } \\
\text { finish }-36, \text { to cease }-3 \text {, to leave }-12 \text {, to enter }-8, \\
\text { to become }-34 \text {, to arrive }-1\end{array}$ \\
\hline Iteratives & $\begin{array}{l}\text { Return }-12 \text {, to repeat }-3 \text {, back (typically preceded by } \\
\text { a verb })-9 \text {, again }-3\end{array}$ \\
\hline Counterfactual conditionals & $3^{\text {rd } \text { conditional }-1}$ \\
\hline It-clefts & It-cleft -1 \\
\hline Temporal clauses & $\begin{array}{l}\text { After }-40, \text { since (in reference to time) }-5 \text {, while }-32, \\
\text { before }-48\end{array}$ \\
\hline
\end{tabular}

The most frequently occurring change of state verbs in the discourse are to become', 'to finish' and 'to start'. This could be explained by the context, as an employee starts processing the material that becomes a finished product as a result.

1. 'A wide variety of techniques are used to finish metals, including grinding and polishing, abrasive blasting and many surface finishing and coating techniques (electroplating, galvanizing, heat treatment, anodizing, powder coating and so forth).' 
Finishing metals is the last stage of metal processing and includes various finishing techniques. Thus, there have been other processing stages that are not explicitly mentioned, but presupposed by the utterance. Background assumptions about the professional context also serve as evidence for the presupposition to survive in the global context.

2. 'Heat is generated by friction, and at forging temperature the rotation ceases.'

The utterance presupposes that the rotation occurs before the forging temperature is reached. However, the first part of the utterance already explicitly states that the forging temperature (the background assumptions provide the reader with the information that forging temperature is very high, thus, generated by heat) is caused by friction. In this context, we presuppose that rotation causes friction. Thus, evaluating this utterance against the global context already provides us with the information that there has been rotation before. The semantic presupposition trigger is supported by the background assumptions.

Another group of presupposition triggers presented in the corpus are implicative verbs and nouns. The verb 'to avoid' occurs 28 times, which constitutes the majority of the findings related to this group of triggers. The verb implies that something is not desirable and, thus, its occurrence can be justified by the fact that the goal of the health and safety encyclopaedia is to avoid accidents related to the industrial failures and human factors. The use of the verb implies the danger or at least the lack of usefulness of something that should be avoided. In the context of the health and safety issues, it could be suggested that avoiding problems constitutes an important matter in this discourse.

3. 'The dangerous practice of removing a hood guard because of narrow clearance on the gauge side can be avoided by clamping a filler board to the table between the gauge and the saw and using it to guide the stock.'

The implicative verb presupposes that it is not recommended to engage in the dangerous practice of removing a hood guard, thus, emphasising the negative connotations associated with the verb. The presupposition survives under negation, as the dangerous practice remains in case it cannot be avoided. Background assumptions about the professional discourse allow the presupposition to survive in the context of the utterance.

Interestingly, the verb 'to happen' that presupposes the accidental nature of an event appears only four times in the discourse, half of them preceded by a tentative modal verb 'may'. This can be explained by the authors' unwillingness to emphasise the negative consequences of not following the safety procedures.

It should also be noted that the word 'an attempt' occurs in the form of a noun. This suggests that the grammatical category itself does not define the 'default' presupposition embedded in the semantic meaning. 
Factive verbs and predicates are presented in the corpus by a very few examples, four of them containing the predicate 'to be aware of'. The use of the predicate can be justified by the transactional (Brown and Yule, 1983: 40 quoted in Rozina, 2013: 11) function of the genre of encyclopaedia, which intends to convey information or 'to make aware' of something. Each of the occurrences of 'to be aware' in the corpus collocates with 'employees' or 'workers', which supports the claim that this factive predicate is utilized in order to fulfil the transactional function of the discourse.

4. 'Carbon monoxide is perhaps the greatest hazard from furnaces and ovens. Since it is colourless and odourless, it frequently reaches toxic levels before the worker becomes aware of it.'

From the analysis conducted at the linguistic level, it can be observed that 'it' refers to hazardous carbon monoxide mentioned in the previous sentence. The presupposition triggered by the factive predicate suggests that carbon dioxide reaches toxic levels. It survives under negation as the toxic level can be reached whether or not the worker is aware of it. The presupposition contributes to the pragmatic meaning construction that emphasises danger and workers' awareness of it. It is supported by background assumptions about the nature of some toxic chemicals. Thus, the presupposition triggered by the factive predicate survives in the global context.

The most frequently occurring iterative in the discourse is an adverb 'back', which means 'returning to an earlier starting point or situation' (Cambridge Dictionary, n.d.: Online). It mostly occurs after verbs as in the following example:

5. 'An important adjunct is the availability of wash-up facilities and clean lockers and dressing rooms, so that workers' clothing remains uncontaminated and workers do not carry toxic materials back into their homes.'

The utterance contains an iterative 'back' collocated with the verb 'to carry', which presupposes that the workers come from their homes to work and return after their shift is over. The background assumptions support the presupposition. It also survives under negation since, if the workers carry toxic materials back into their homes, the utterance still presupposes that they have arrived from their homes to work.

With the exception of temporal clauses, syntactic presupposition triggers do not frequently occur in the discourse under analysis. In fact, the observed cases of counterfactual conditional and it-cleft demonstrate that the grammatical patterns do not automatically trigger the presupposition or the presupposition is cancelled by the co-text or the linguistic context of an utterance.

The empirical discussion has demonstrated the interconnectedness between the semantic and the pragmatic aspects of meaning in the professional discourse via the concept of presupposition. Examples 1-5 contain 
the semantic presupposition triggers that have been supported by the pragmatic presuppositions, i.e. background assumptions about the field of mechanical engineering that the target audience is expected to have. Consequently, the study links the levels of the semantic aspect of meaning represented by the lexical and syntactic presupposition triggers and the pragmatic aspect of meaning construction. Moreover, the professional discourse readers' background assumptions are regarded as pragmatic presuppositions rather than conversational implicatures as the background knowledge is assumed to be accessible at the level of the entire discourse community (i.e. language users involved in the communication in the field of mechanical engineering) rather than at the level of individual language users.

\section{CONCLUSIONS}

The theoretical background offers three distinctions: between entailment and presupposition; between semantic and pragmatic presupposition and between presupposition and conversational implicature. These considerations place presupposition in the semantics-pragmatics interface, as it is argued that the concept is both semantic and pragmatic in terms of meaning. In the semantic theories of meaning, presupposition is defined by logical relations similarly to entailment; however, in the pragmatic theories, presupposition is more 'collective' or accepted by all conversational participants than conversational implicature.

Presupposition triggers, such as change of state words and temporal clauses, occur in the mechanical engineering discourse most frequently. This can be explained by the context of the professional discourse that focuses on the sequence of steps in material processing and the temporal periods, in which these steps are to be completed. Thus, the background assumptions and contextual variables usually support the occurrence of certain linguistic forms in the discourse under analysis.

The linguistic form of an utterance can act as a trigger for further inferential process of the communication participants, but communication is successful only in case if the utterance is either consistent with the current background assumptions of an addressee or the assumptions are adjusted in the linguistic context. This process demonstrates that presupposition is both a semantic and a pragmatic phenomenon and affects the meaning construction from both linguistic and non-linguistic perspectives.

\section{REFERENCES}

Ariel, M. (2010) Defining Pragmatics. Cambridge: Cambridge University Press.

Cambridge Dictionary (n. d.) Available from https://dictionary.cambridge.org/ [Accessed on 19 June 2019].

Dörnyei, Z. (2007) Research Methods in Applied Linguistics. Oxford: Oxford University Press. Huang, Y. (2007) Pragmatics. Oxford: Oxford University Press.

Huang, Y. (2012) The Oxford Dictionary of Pragmatics. Oxford: Oxford University Press. 
Levinson, S. C. (1983) Pragmatics. Cambridge: Cambridge University Press.

Mey, J. L. (1993) Pragmatics. Oxford: Blackwell Publishers.

Rozina, G. (2013) Banking and Finance Discourse: Towards Metaphor in Use. Riga: University of Latvia.

Saeed, J. I. (2003) Semantics. Oxford: Blackwell Publishing.

Sperber, D. and Wilson, D. (1995) Relevance. Communication and Cognition. Oxford: Blackwell Publishing.

\section{SOURCES ANALYSED}

Stellman, J. M. and Parish, J. (eds.), (2011) Encyclopaedia of Occupational Health and Safety, Chapters 82, 86. Geneva: International Labour Organization. Available from: http:// www.iloencyclopaedia.org/part-xiii-12343/woodworking [Accessed on 18 June 2019].

Jekaterina Čerņevska ( $\mathrm{PhD}$ Candidate, Lecturer) is currently working at the University of Latvia. Her research interests include pragmatics and the use of English in professional discourse. The $\mathrm{PhD}$ dissertation discusses the pragmatic meaning construction in mechanical engineering discourse. E-mail: jekaterina.cernevska@gmail.com. 